\title{
Mapping the decision to quit: A refinement and test of the unfolding model of voluntary turnover
}

\author{
Kevin Morrell \\ The Local Government Centre \\ Warwick Business School \\ University of Warwick \\ Coventry \\ CV4 7AL \\ United Kingdom
}

John Loan-Clarke, John Arnold and Adrian Wilkinson*

The Business School

Loughborough University

Loughborough

LE11 3TU

United Kingdom

*Griffith Business School,

Nathan,4111,QLD

Australia 


\section{$\underline{\text { Abstract }}$}

We report a test of an influential theory of employee turnover: the unfolding model (Lee \& Mitchell, 1994: Lee, Mitchell, Holtom, McDaniel \& Hill, 1999). We describe and critique this classificatory model, and propose both theory-based and empirical refinements. The two extant tests of the current version of the model have both been with accountants in the United States, so the generalizability of the model is as yet unproven. We present results of an attempt to classify 352 nurse leavers from the United Kingdom's National Health Service using the unfolding model. In contrast to the findings of Lee et al. (1999), the model failed to classify a substantial number of nurse leavers, and specific hypotheses derived from the model received only partial support. Classification failures were investigated using both quantitative and qualitative data. Leavers were more likely to be classified if they had no dependants and described their quit as avoidable. Although the unfolding model incorporates more kinds of turnover than traditional turnover models, such systematic classification failure casts doubt on claims that it offers a comprehensive account of turnover. We explain failures with reference to: (i) shortcomings in a key measure; (ii) the characteristics of the occupational group studied; and (iii) the extremely tight labor market for this group of leavers.

Keywords: employee turnover, unfolding model, image theory, United Kingdom, nurses, turnover. 


\section{Mapping the decision to quit:}

\section{A refinement and test of the unfolding model of voluntary turnover}

The unfolding model (Lee \& Mitchell, 1994) is a retrospective, classificatory account of voluntary turnover that treats quitting as a decision process. It is widely cited (Allen \& Griffeth, 2001; Cohen 1999; Griffeth, Gaertner \& Sager, 1999; Hom \& Kinicki, 2001; Price, 2000) but to date has received limited empirical attention, despite Maertz and Campion's (1998) advocacy for its development. The latest version (Lee, Mitchell, Holtom, McDaniel \& Hill, 1999) has been critiqued by Maertz and Campion, (2004) in their innovative synthesis of process and content turnover theories. However, we were able to locate just two published empirical tests of the unfolding model: Lee $e t$ al. (1999) themselves, and very recently, Donnelly and Quirin (2006). Both these papers report data from accountants in the United States. Bozeman and Perrewe (2001) stress the importance of critically testing theory, particularly before extensive application. Without such testing, incomplete theory can become stabilized in the literature. We believed this could apply to the unfolding model, and we therefore sought to subject it to rigorous but fair empirical examination in a context other than US accountants.

Recent debate has hailed the development of improved theory through effective testing as an important contribution to knowledge (Edwards, 2002). However, studies have to accomplish testing that is flexible enough to allow for conceptual critique and theory development, whilst simultaneously preserving the logic of a repeated test. There must be sufficient similarity, yet without development the test will be open to the charge of not making a contribution (Hendrick, 1991). Following Eden (2002, p. 842), 
for a test to be sufficiently similar, it must allow examination of the 'same hypothesized relationships among the same theoretical constructs'. Given that this important requirement is met, the most potentially useful tests will be those that differ as much as possible from the prior study or studies, to establish generality (Rosenthal, 1991). As well as the where and how, difference extends to who carries out the test (Hendrick, 1991). Researchers unconnected with the original authors of a theory are preferable, since they are regarded as more objective (Rosenthal, 1991). This is not to imply that originators of a theory are somehow dishonest - simply that they may be somewhat entrenched in certain ways of thinking about the theory, and that outsiders are better placed to offer new perspectives to take the theory forward.

With these issues in mind, our objectives in this study were: (i) to conduct a theoretical and methodological critique of the unfolding model; (ii) to propose refinements, without substantively changing its core concepts; (iii) to test the model in a new context and evaluate its effectiveness, and; (iv) depending on our findings, to specify ways in which the unfolding model should be developed.

\section{The Unfolding Model}

This has three main features. First, the theoretical basis is image theory (Beach 1990), an alternative to accounts of decision-making that emphasize rational choice. Image theory incorporates rational choice theory, but stresses the primacy of intuitive or nonrational elements in decision making. A person may use one or more of three types of images, or schematic knowledge structures, for decision making. These relate to values (the decision maker's principles), trajectories (desired goals) and strategies (how to achieve those goals). An option is adopted or rejected depending on its compatibility or fit with subsets of images. 
Second, the model features two constructs new to turnover research: 'shock' and 'script'. A shock is a specific event that prompts people to consider leaving, which in earlier work is compared to 'a disturbance in time-series analysis', where the act of interpretation is 'part of an ongoing context' (Lee \& Mitchell, 1994, pp. 60-1). A script is variously defined as a 'preexisting plan of action' (Lee et al., 1999, p. 451) and as 'routinized... programmed behavior' (Lee \& Mitchell, 1994, p. 71).

Third, the model shows how people leave in different and distinct ways, represented by five mutually exclusive decision paths (see Table 1). In paths 1, 2 and 3, the quit begins with a shock; a single, jarring event prompting thoughts of quitting. Path 1 leavers carry out an extant plan (script) to quit. They do not search for or evaluate alternatives, or consider likely offers, but leave quickly regardless of image violation(s) or satisfaction. In paths 2 and 3, shock prompts image violation; that is, dissonance between the present job and one or more images. This can be so severe that satisfaction is irrelevant as a quit is triggered without search / evaluation or a job offer (path 2). Alternatively, it can lead to dissatisfaction, then search / evaluation, and quit after a job offer (path 3). An offer need not be definite, but only needs to be perceived as 'highly likely' (Lee et al., 1999). In paths 4a and 4b, leavers do not have a shock, but experience image violation more gradually. This can result in quitting without search / evaluation or an offer (path 4a). Alternatively, dissatisfaction can lead to quitting after search / evaluation and an offer (path 4b). Lee et al. (1999, p. 451) state that identification of other paths to quitting would indicate falsification of the unfolding model.

Insert Table 1 about here 
The model therefore specifies that people quit in five prototypical ways, in contrast to accounts that propose a normative path from (say) job dissatisfaction to organizational exit (see Maertz \& Campion, 1998). Lee et al. (1999) tested the model on 229 accountant leavers and classified 212, or 92.6\%. They identified and tested eleven hypotheses; all but one was wholly corroborated. The principal hypotheses concerned the classification of leavers, the speed at which decisions unfold, and the role of job satisfaction. More recently, Donnelly and Quirin (2006) have reported a study of 84 US accountants, 46 of whom left their jobs. They found that the unfolding model successfully classified 42 of the 46 leavers, and that shocks were more likely to be part of the decision processes culminating in leaving than those culminating in staying. Donnelly and Quirin's study has some limitations. As well as the comparatively small sample size, their response rate was just $14 \%$. Also, their respondents are restricted to the same occupational group (accountants in the US) as Lee et al. (1999). This is a serious limitation given that occupational heterogeneity is a prerequisite for assessing the external validity of a model in turnover (Hom and Kinicki, 2001).

In summary, the unfolding model is a relatively novel development in turnover research but requires critical testing to examine its potential usefulness. By conducting the first study of the model using a different occupational group (nurses versus accountants); in a different country (UK versus USA); in a different sector (public versus private), we sought to achieve the research objectives stated above.

\section{Critical Analysis of the Model and its Operationalization}

In order to achieve a valid test of the unfolding model, we felt it was necessary to address four issues concerning the model and the way in which its key constructs 
have been measured. First, in some cases, Lee et al. (1999) used one item to tap more than one construct. This is problematic because it leaves the instrument open to the charge of forcing the data, and undermining discriminant validity (Maertz \& Campion, 2004). For example, the yes / no item, 'If you accepted a job offer you had in hand, was it originally an unsolicited offer or inquiry?', was used by Lee et al. to tap three constructs: shock, script and offers. Although we sought to retain the Lee et al. measures where possible, we refined the classification rules so that no measure was used to tap more than one construct, since this jeopardizes discriminant validity.

Second, the original survey does not ask leavers why they left. It is useful to ask leavers about underlying reasons since this throws more light on the decision as a whole. Incorporating a sense of the context for the quit enhances understanding (Maertz \& Campion, 1998; Morrell, Loan-Clarke \& Wilkinson, 2004a). The survey used in this study therefore followed Campion (1991) by including open-ended questions concerning respondents' reasons for leaving, and also one concerning turnover avoidability (Abelson, 1987).

Third, a related criticism that could be leveled at the model is that it relies too heavily on dichotomous measures. Using a dichotomous measure to tap a construct, rather than a scalar one, means there are fewer data points along which respondents' scores may lie. The danger here is that there may be a failure to capture or reflect construct complexity, and classification can become a matter of fitting the phenomenon to the model (a Procrustean bed), rather than seeing whether the model fits the phenomenon (by testing its assumptions critically). We therefore changed some dichotomous measures into scalar ones. Nevertheless, we retained Lee et al's (1999) dichotomous items where we decided it was possible to construe the construct assessed 
as present $v s$. absent. We were mindful that if we changed too many measures, any differences between our findings and those of previous studies might be seen as being attributable mainly to those changes rather than the unfolding model per $s e^{1}$.

Fourth, with respect to the shock construct, we followed Lee et al. (1999) by asking about a specific event and for a description of the event. But because this concept is only defined rather briefly in work to date, we also included some scaled items anchored by semantic opposites to test hypothesised dimensions of shock, developing and extending the Lee and Mitchell (1994) and Lee et al. (1999) approach to analysing the characteristics of shocks. We wanted to try to enhance understanding of the nature of the shock and offer further insight into the nature of the quit and (contingent on the findings) offer scope to explore any classification failures. These are single-item standalone measures (though scaled rather than dichotomous) since we construe the dimensions as orthogonal and global. Accordingly, the use of the sum of facet measures would be inconsistent. Loo (2002) suggests that single-item measures may be used with caution. Although these prohibit assessment of internal reliability, they may be appropriate where the underlying constructs are homogeneous, a view supported by earlier research into measures of global job satisfaction (Wanous \& Reichers, 1996; Wanous, Reichers, \& Hudy, 1997). Other recent work (Nagy, 2002) suggests that as well as having potentially greater face validity, single-item measures may be used more flexibly in analysis and that 'the primary concern' in instrument design should be 'the extent to which the instrument represents and measures the construct' (pp. 79-80). Thus, we contend that they are appropriate here for extending theory.

\footnotetext{
${ }^{1}$ Thanks to an anonymous reviewer for helping us to develop and clarify this point.
} 


\section{Hypothesis Tests}

As indicated earlier, in this study we test several hypotheses first put forward by Lee et al. (1999). These hypotheses go to the heart of the unfolding model of turnover and disconfirmation would be a major setback for it. The hypotheses and rationales for them are as follows.

One of the key theoretical contributions of the unfolding model is the notion that not all decisions to quit will unfold with the same speed. Where there is a single, jarring event that precipitates thoughts of quitting (i.e. a shock), the unfolding model predicts that turnover will be faster than where there is no shock, because of the shock's galvanising effects. Lee et al. (1999) tested this with the following hypotheses relating to the role of shocks (a feature of path 3 , but not path $4 \mathrm{a} / \mathrm{b}$ quits) and decision duration.

Hypothesis 1a. The duration between the first thoughts of quitting and a decision to leave will be shorter in path 3 than in path $4 b$.

Hypothesis $1 b$. The duration between a decision to leave and actual quitting will be shorter in path 3 than in path $4 b$

Since path 3 shocks are associated with low job satisfaction, it is reasonable to hypothesise that work-related shocks (as opposed to shocks outside the work context) are likely to be more prevalent among this type of quit. This is consistent with the belief that quits which are scripted (path 1), or where job satisfaction is irrelevant (path 2) are more likely to be prompted by personal events. These pathways reflect the centrality of non-work domain variables, such as the role of dependants, in some quits (Cohen, 1999; Price \& Mueller, 1986; Price, 2000).

Hypothesis 2. Path 3 is positively associated with work-related shocks. 
Since path $4 \mathrm{~b}$ quits unfold over some time, and represent a gradual disenchantment with the organization, one would expect that job satisfaction would be lower than in path 3 - where a jarring event was the precursor to the quit. Lee et al. (1999) made this hypothesis even though satisfaction is specified as low in both path 3 and path $4 \mathrm{~b}$. They justify their hypothesis by pointing out that in path 3 a shock is the precipitating event (and by implication, satisfaction until that point would likely have been high or at least moderate), whereas in path $4 \mathrm{~b}$ low satisfaction is what triggers job search and leaving

Hypothesis $3 a$. Job satisfaction will be higher in path 3 than in path $4 b$.

In terms of the theory underpinning the unfolding model, 'image violation' is a logical precursor to non-scripted quits. Images are personal principles, or decision schemata, reflecting the decision maker's goals, personal values, and strategies to achieve those goals (Beach, 1990; Beach \& Mitchell, 1998). In a work domain, where actions are incompatible with personal images (i.e. where there is image violation), this will result in job dissatisfaction.

Hypothesis 3b. Job satisfaction is negatively correlated with image violation.

To summarise, our critique indicates a number of problems with the unfolding model of turnover and its operationalization. Our study therefore incorporates theorydriven improvements to operationalization, so as to elevate the potential contribution. We aim to test the classificatory power of the unfolding model, to use any misclassifications to develop the model, and to test the specific hypotheses described 
above. Choice of context was motivated by wanting to enhance dissimilarity (Eden, 2002). This can help to identify parameters that potentially limit the generalizability of findings (Amir \& Sharon, 1991; Hubbard, Vetter \& Little, 1998; Peterson, 2001). Nurses in the United Kingdom were chosen as the target occupational group because quitting patterns among nurses are seen as atypical and hard to model, given the widespread availability of alternatives (Hom \& Kinicki, 2001). Although an earlier version of the unfolding model was tested on US nurses (Lee et al., 1996), the process of classifying used then is very different from the operationalization of the survey in Lee et al. (1999), and its adaptation for use here. Lee et al. (1996) began with theoretical constructs that framed an interview schedule and were used to generate the interview data. These data were then used to classify leavers by employing a series of dichotomies, which were judged by data coders on the basis of the (often complex) interview responses. The most recent version of the unfolding model uses a substantively different method (closed item survey). Hence our context helps us to test the current model's claim to generality.

\section{Method}

\section{Procedure and Sample}

Eight Trusts ('Trust' can be read as 'large hospital, or group of hospitals') in the United Kingdom's National Health Service (NHS) participated in this research. They are diverse in terms of location, size and type: four are medium sized and rural; four are large and city-based teaching hospitals. Trusts mailed surveys to full-time, qualified, voluntary nurse leavers who left in the year immediately preceding data collection. Respondents returned these direct to the authors to preserve confidentiality. Of 1,190 surveys, 368 were returned. Twenty-four were known to have been undelivered 
because of inaccurate mailing details. Sixteen were excluded because the respondent was not a nurse (three cases), the quit was involuntary (ten cases), or there were missing data (three cases). The final sample size is 352 , a response rate of $31 \%$, significantly higher than in Lee et al. (1999) $\left(20 \%, \chi^{2}=7.57, p<0.01,1\right.$ d.f.) and more than double Donnelly and Quirin (2006) $\left(14 \%, \chi^{2}=52.4, p<0.001,1\right.$ d.f.). This rate is high for an unprompted survey (Owen \& Jones, 1994).

Turnover in this context (nurses in the UK NHS) is rarely organizationally driven (involuntary). However, to preclude cases of involuntary turnover being counted, we had three 'filtering' stages in the study. First, data on leavers were collected via an organizational database that purportedly excluded involuntary turnover. Second, we included the dichotomous survey item 'Did you leave voluntarily (this includes early retirement)?'; a response ' no' excluded leavers. Finally, responses to two open ended items ('What was the primary reason for leaving your prior post?' and 'Please describe any other important reasons') were content-analyzed to prevent any cases of involuntary turnover being included.

\section{Measures of unfolding model constructs}

An 8-item, 5-point scale (alpha 0.89) was used to assess image violations. Wording was necessarily altered slightly from Lee et al. (1999) to reflect the change in context (e.g. 'Trust' was used rather than 'firm'). The first four of these (on a scale of Not compatible [1] ... Very Compatible [5]), were: 'How compatible were your personal values / ethics with those of your former Trust?'; 'How compatible were your professional values / ethics with those of your former Trust?'; 'How compatible were your personal goals with those of your former Trust?'; and 'How compatible were your 
professional goals with those of your former Trust?'. The last four (on a scale of Strongly Disagree [1] ... Strongly Agree [5]), were: 'If I had stayed, I would have been able to achieve most of my career goals'; 'If I had stayed, I would have been able to achieve most of my personal goals'; 'At the Trust, my career was progressing as I expected'; 'At the Trust, my personal goals were progressing as I expected'. A response of 1 or 2 to any of these eight questions was taken to signal image violation.

The measure of shock followed Lee et al. (1999) by asking 'Was there a single, particular event that caused you to think about leaving?' An answer of yes, and/or a description of an event in response to an open-ended invitation to give one, was deemed to constitute a shock. Unlike Lee et al. (1999), we excluded questions concerning unsolicited offers because we felt they were not applicable to this context, where receipt of unsolicited offers is very rare (Morrell et al., 2004a). In order to shed further light on the nature of shocks, we also adapted and extended Lee et al. (1999) by asking the following five questions, with responses on a 1-5 scale anchored by semantic opposites appropriate to each question: 'To what extent was the event expected or unexpected?' 'To what extent was the event a positive or negative experience?'; 'Did the event involve personal issues or work issues?'; 'How much did the event influence your final decision to leave?'; Who else at work did the event affect?

A script was deemed to be present if a respondent agreed (i.e. scored above the midpoint) on any of the following 5-point Likert items: 'I have left a job before for essentially the same reasons (i.e. very similar circumstances)'; 'At the time I left my job, I had already determined that I would leave IF a certain event were to occur (e.g. not receiving a promotion)'; 'My decision to leave was influenced by a colleague (or 
colleagues) leaving'. The first two items were the same as Lee et al. (1999). We added the last one to reflect the potentially social origin of a script.

Respondents were deemed to have received a job offer if they agreed (i.e. scored above the mid point) on either of the two 5-point Likert items: 'I had at least one definite job offer before I finally left'; 'I didn't leave until I had a definite job to go to'; or (as per Lee et al. 1999), if there was a non-zero response to either of these: 'How many acceptable alternative jobs did your search produce before you left (i.e. how many could you have realistically accepted)?'; 'How many total job offers did you have before you left?'.

We considered two of the items used to measure search by Lee et al. (1999) to be inappropriate because they were worded in a way that made their applicability to the respondent conditional upon whether or not they had received an offer. However in common with Lee et al. (1999) we retained the item, 'before you left, how comprehensive was your search for another job', to tap search. Again in common with Lee et al., we used a 5-point scale with anchors from 'no search' through to 'comprehensive search'. Any response other than 'no search' was taken as evidence of search.

Measures for evaluation of alternatives were based on Lee et al.'s (1999, p. 461) dichotomous items though we used two five-point Likert agree-disagree items to reflect that evaluation (in common with related behaviors, such as search) is not dichotomous (Maertz and Campion, 1998). Agreement to, 'I weighed up a range of work and / or non-work alternatives before leaving' was counted as evaluation for classification purposes (responses at the midpoint 'neither agree nor disagree' were not counted as evaluation). However, if respondents agreed to the second item, 'I left without 
evaluating any alternatives' this was classified as no evaluation, irrespective of the response to the first item.

Two other scales were closely based on Lee et al. (1999). A 13-item, 5-point scale tapped job satisfaction; and a 4 item, 5-point scale tapped professional attitudes. Alphas for these were reasonably high (both 0.84); a principal components factor analysis of the job satisfaction scale indicated a single factor structure (it is not meaningful to perform this procedure on the professional attitudes scale, which has only four items). Hence it is appropriate to summarize each as a single summated scale.

Following Table 1, leavers were classified as follows:

1 Shock + Script + No Search + No Evaluation + No Likely Offer

2 Shock + Image Violation (IV) + No Search + No Evaluation + No Likely Offer

3 Shock + IV + Dissatisfaction + Either Search or Evaluation + Likely Offer

4a No Shock + IV + Dissatisfaction + No Search + No Evaluation + No Likely Offer

4b No Shock + IV + Dissatisfaction + Either Search or Evaluation + Likely Offer

\section{Other measures}

These other measures were included either to allow us to conduct the hypothesis tests or to help in understanding the operation and limitations of the unfolding model. They have also figured in other published research papers on the model.

Decision saliency. One item on a 5-point agree-disagree scale: 'At the time I left, it seemed clear to me that I had to decide there and then whether to stay or go'. This was based on an item in the survey used by Lee et al. (1999) (however, it was not discussed in Lee et al. - we thank Prof. Lee for allowing us a copy of the survey). 
Avoidability. Again, one item was used: 'There are things that the [Trust] could have done that might have caused me to stay' - this too was assessed on a 5-point agree-disagree scale. This item wording is also the same as in Lee et al. (1999).

Tenure was measured in days, from demographic data.

Two measures were used for speed of decision, both recorded in days. These were: 'After your first thoughts about leaving, how long did it take you to make the final decision to leave?', and 'After you made the final decision to leave, how long did you stay on the job before you actually left?').

\section{Results}

Table 2 shows summary statistics and classification results, enabling basic comparison between this study and Lee et al. (1999). Our respondents reported significantly lower satisfaction $(t=-14.84, p<0.001,2$-tailed). Differences in age ( $t=-$ $10.5)$, tenure $(t=-14.09)$ and $\operatorname{sex}(Z=15.04)$ were all significant $(p<0.001,2$-tailed test $)$, with our respondents being younger, of shorter tenure and more likely to be female than the Lee et al. respondents.

Insert Table 2 about here

Ability of the unfolding model to classify leavers

The relevant figures are shown in Table 2. Most leavers reported an offer, or likely offer (339 of 352), and thus could not be classified in paths 1, 2 or 4a. Only $0.9 \%$ of our respondents fell into one of these three paths, compared with $9.2 \%$ in Lee $e t$ al. (1999), and 63.0\% in Donnelly and Quirin (2006). This is not entirely surprising 
because one common feature of nursing turnover is the ready availability of alternative opportunities (Hom \& Kinicki, 2001). We will return to this issue later.

More importantly for our immediate concerns, 81 (23\%) of leavers were unclassifiable. This is significantly higher $\left(\chi^{2}=33.14, p<0.001\right.$, 1d.f. $)$ than Lee et al. (1999), who report $17(7.4 \%)$ unclassified cases. It is also significantly higher than Donnelly and Quirin's 4 unclassified cases $(8.7 \%)\left(\chi^{2}=4.91 p<.05,1\right.$ d.f $)$. As a next step we identified and described instances of classification failure (below). These constitute null pathways, i.e. paths not captured in Table 1 . The numbers in parentheses represent the number of cases in each path. To aid presentation, Image Violation is shortened to IV and Evaluation is shortened to Eval:

1 Shock + No Script + No IV + No Dissatisfaction + No Search + No Eval + Offer (1)

2 Shock + No IV + Dissatisfaction + Search or Eval + No Offer (3)

3 Shock + No IV + Dissatisfaction + Search or Eval + Offer (11)

4 Shock + No IV + No Dissatisfaction + Search or Eval + Offer (7)

5 Shock + No IV + Dissatisfaction + No Search + No Eval + Offer (2)

6 Shock + IV + Dissatisfaction + Search or Eval + No Offer (6)

7 Shock + IV + Dissatisfaction + No Search + No Eval + Offer (4)

8 Shock + IV + No Dissatisfaction + No Search + No Eval + Offer (1)

9 Shock + IV + No Dissatisfaction + Search or Eval + Offer (4)

10 No Shock + No IV + Dissatisfaction + Search or Eval + Offer (26)

11 No Shock + No IV + No Dissatisfaction + Search or Eval + Offer (9)

12 No Shock + IV + No Dissatisfaction + Search or Eval + Offer (5)

13 No Shock + IV + Dissatisfaction + Search or Eval + No Offer (1) 
14 No Shock + IV + Dissatisfaction + No Search + No Eval + Offer (1)

These findings challenge the generalizability of the unfolding model as a classificatory tool. To see if missing data meant some constructs were inadequately assessed in our study, we checked each questionnaire. In no case could missing data have made an unclassifiable case classifiable. Also, failure to report image violation or job dissatisfaction was not attributable to incomplete responses. In only 5 cases (leavers in null paths 7 and 14 above) could different scores for evaluation possibly have made unclassifiable leavers classifiable. This is noteworthy since it helps us to be confident that our changes to the evaluation items (which we felt were necessary to reflect that evaluation is not dichotomous) did not influence classification adversely.

\section{Results of hypothesis tests}

The paucity of nurses classified in paths 1,2 or 4a made it impossible to test all of Lee et al.'s (1999) hypotheses. That leaves the hypotheses we specified in the introduction. All were corroborated by Lee et al. (1999).

Regarding hypothesis 1, following Lee et al. (1999), logistic regression was used to analyze the interaction between decision time and pathway. The basic form for such a function can be expressed as: $p$ (event) $/ p$ (no event $)=\mathrm{a}+\mathrm{b}_{1} \mathrm{x}_{1}+\mathrm{b}_{2} \mathrm{x}_{2}+\ldots \mathrm{b}_{n} \mathrm{x}_{n}+$ $\mathrm{e}$, where $p$ (event) / $p$ (no event) is the log odds ratio, a is a constant, $\mathrm{x}_{n}$ an independent variable, $b_{n}$ a coefficient estimating the change in log odds, e is an error term. Both decision time variables were entered as the first and only step, using a cut-off value for the logistic function of 0.57 , to reflect the difference in group proportions (150 leavers in path $4 \mathrm{~b} /[150+112$ leavers in path 3$])$. The first decision time variable (time 
between first thoughts of quitting and decision to leave) was significant $\left(\chi^{2}=6.24\right.$, $p<0.05$ ), and so H1a was corroborated. The second decision time variable (time between decision to leave and actually leaving) was not significant, and so $\mathrm{H} 1 \mathrm{~b}$ was not corroborated.

To test $\mathrm{H} 2$, we ran a one-tailed independent samples $t$-test, comparing mean scores on the work-related shock item for path 3 shocks with all non-path 3 shocks. The scores for path 3 shocks were significantly lower (i.e. more work-related) than shocks for other paths $(t=2.62, p<0.005)$. Thus we found strong support for $\mathrm{H} 2$.

Hypothesis 3a was not supported. Mean satisfaction was higher in path 3 $(\bar{x}=2.71)$ than $4 \mathrm{~b}(\bar{x}=2.64)$, but this was not significant on a one-tailed independent samples $t$-test, $(t=0.94) . \quad$ Hypothesis $3 \mathrm{~b}$ was supported. Correlations between the 8 image violation items and mean job satisfaction were all significant $(p<0.001)$ and ranged from -0.59 to -0.47 .

\section{Exploration of classification failures}

Several variables can be used to try to predict whether a case was unable to be classified by the unfolding model. These variables could not be used in the initial classification process however, because their explanatory power would then be counted twice - beforehand to decide classification, and afterwards to explain the differences in classification. Accordingly, we used the following five metric variables: decision saliency, decision duration, and avoidability (these three offer additional information relating to the nature of the decision itself); and tenure and professional attitudes (these last two indirectly indicate commitment to the organization or profession). Five nonmetric (dummy) variables from the demographic section of the survey were also 
included: level (whether or not the leaver was the lowest grade); sex; whether the leaver reported being the chief wage earner; whether the leaver was still working as a nurse; whether the leaver reported having dependants.

Discriminant analysis and logistic regression are both suitable ways to model the outcome of a binary dependent variable (here, leavers able to be classified versus those unable to be classified). However, logistic regression is preferable since it is more capable of handling several dummy variables simultaneously and does not assume normality (Hair, Anderson, Tatham \& Black, 1998). Using forward entry of covariates and a removal criterion based on the significance of the Wald statistic (at 10\%), we identified two predictor variables: avoidability, and whether the leaver had dependants. These were then entered to form the final model. Goodness-of-fit was assessed using change in log likelihood (Hosmer \& Lemeshow, 1989). For our model this value was highly significant $\left(\chi^{2}=20.3, p<0.001,3\right.$ d.f $)$. For this procedure there were 25 missing cases, giving a sample of 327 leavers, of whom 77 were unclassifiable. $T$ - and chisquare tests failed to identify any significant differences between the missing cases and those included in the analysis across the following measures: decision time, saliency, professional attitudes, tenure, age, gender. This suggests that missing data would be unlikely to affect the results of our logistic model of classification failure.

Thus we can conclude that leavers were on the whole more likely to be classified by the unfolding model where they reported their decision as avoidable and they had no dependants. This analysis was post hoc rather than theory driven, but it does suggest that the model is relatively poor at explaining quits that are (broadly) influenced by factors outside the control of managers, including non-work domain variables such as spouse relocation and family care commitments (Cohen, 1999). This finding probably 
reflects the substantial gender difference between this sample ( $91 \%$ female), and both Lee et al.'s (1999) sample (31\% female) and Donnelly and Quirin's (2006) sample (51\% male).

\section{Exploration of Image Violation}

Reading through respondents' answers to the open items, evidence of image violation was found in 41 cases (of a total of 60) where the current scale did not indicate image violation. Brief extracts that illustrate where image violation could be additionally identified are given below:

"More time to my family." (Value image).

"I left so I could concentrate on my application to emigrate." (Trajectory image).

"Needed a new challenge and change of direction." (Strategic image).

More detailed content analysis indicated that where respondents left for purely personal reasons, the scale often did not elicit valid responses. For example, one wrote: "I thoroughly enjoyed my job... the only reason for leaving was to move, I missed the sea." However, in response to the items, "How compatible were your personal goals with those of your former Trust?' and 'If I had stayed, I would have been able to achieve most of my personal goals', this respondent answered 5 ('very compatible') and 5 ('strongly agree'). This apparent contradiction can be explained if this respondent interpreted the phrase 'personal goals' as relating solely to life at work. This inference is supported by other responses. For example, eight other respondents described relocating due to non-work factors (i.e. where personal goals were incompatible with work goals), but did not report image violation on the current scale. 


\section{Discussion}

The results of this study challenge the idea that the unfolding model offers a generic account of turnover. This test incorporates contextual differences intended to identify parameters that could limit the model's generalizability (Eden, 2002; Peterson, 2001). The high number of alternative opportunities prevented leavers being classified in paths 1,2 and 4a. 81 leavers (23\%) were not classifiable - a significantly higher proportion than in Lee et al. (1999) and Donnelly and Quirin (2006). Unclassified cases were largely due to non-work image violations not being detected with the extant scale. Hypotheses derived from the model that were tested and supported by Lee et al. (1999) received mixed support here. We checked for whether changes in our classification rules could have made a significant difference, and we used additional data to identify likely weaknesses in the extant measures. We contend therefore that our study is a more valid test of the unfolding model than previous research has offered.

A key issue, of course, is why our findings are in some respects less supportive of the unfolding model than those of Lee et al. (1999) and Donnelly and Quirin (2006). One possibility is that the unfolding model is inherently deficient in its specification and/or combination of key constructs. For example, the script construct is defined in more than one way in Lee and colleagues' writings, and the construct of image violation may be an unnecessarily elaborate way of expressing other constructs already reflected in the model, such as satisfaction (or lack of it). As Maertz and Campion (2004, p. 568) point out, it seems likely that image violation can actually be the shock that reduces job satisfaction. We have some sympathy with suggestions of this kind. On the whole, however, we have been more concerned to operationalize the unfolding model better in order to test it effectively, than to challenge or change its key constructs. This means 
our data cannot be used to conclude that a revised version of the model is better than the present one. Nevertheless, below we make suggestions for how the model might be altered.

A second possible reason for our findings is that the unfolding model is largely "on the right track", but in its current form has a limited range of convenience, and needs to be operationalized and/or developed rather differently in order to apply to a wider range of labor market conditions. We believe our data are generally consistent with this position. We suggest our findings reflect typical differences in the way turnover decisions are enacted across the two samples (US accountants in Lee et al. 1999, and Donnelly \& Quirin, 2006, vs. UK nurses here). The differences in our rates of classification success are likely partly due to: (i) variations in the labor market and nature of the employment relationship (notwithstanding that accountants are in demand, UK nurses working in the NHS can more easily find alternative, similar job opportunities); and (ii) the impacts of gender and role conflict (Maertz \& Griffeth, 2004) (non-work domain variables are likely to be more significant for women).

We will now elaborate on these observations with a more detailed assessment of: (i) the roles played by the unfolding model's core constructs; (ii) the model's effectiveness in classifying leavers' decision processes; and (iii) the impact of context on the generalizability of the model.

\section{Core Constructs}

Shocks. We found strong evidence suggesting that a single, jarring event plays a part in many decisions to quit. Shocks can be linked to other ideas in the existing literature. For example, they may be necessary to overcome inertia resulting from sunk costs, or employees' wish to retain employment (Sheridan \& Abelson, 1983), or to 
overcome embeddedness (Mitchell et al., 2001). We suggest exploration of the role of shocks is a good basis for future empirical research in turnover (Morrell et al., 2004a). Conceptually, though, the notion of shock may be problematic because it is defined partly in terms of its consequences for a person's cognition and/or affect. ${ }^{2}$ Such consequences depend both on the occurrence that produced the shock and on individual differences in reactions to it. Perhaps a fruitful way forward would be to develop a typology of work events that potentially lead a person to consider leaving, and assess separately whether individuals are indeed considering leaving.

Scripts. Although 146 leavers reported a script using our scale, only two were identified as following path 1 quits. The vast majority (339 / 352) of nurses reported offers, and so opportunities to be classified as path 1 were limited. This is perhaps a function of the labor market, since nurses typically have plentiful alternative opportunities, and often quit without having a definite job offer (Hom \& Kinicki 2001). However, this ready-to-hand explanation ignores the possibility that scripted quits may be more prevalent, but the current classification system fails to identify them. Maertz and Campion (2004) make a similar argument, and report that $18 \%$ of the leavers in their study had definite plans to leave at a pre-determined time. These can be considered scripted quits, but would not readily be classified as such by the unfolding model and its measures. Failure to detect scripts may be because the current scale is inadequate, or because a remotely administered survey is less able to detect scripts than a semi-structured interview, which affords greater opportunity for analyzing narrative (Lee et al., 1996), albeit a narrative that may be co-constructed rather than elicited.

\footnotetext{
${ }^{2}$ We thank an anonymous referee for highlighting this.
} 
Image Violation. One might have expected some leavers simultaneously to report fit for some images / contexts and violation for other images / contexts, but this seemed to be relatively rare. Instead, leavers tended to experience image violation either across many contexts or in none. Both in this study and in Lee et al. (1999), the main reason for non-classification was respondents' failure to report image violation. Our use of additional open items and exploration of reasons for leaving identified the likely nature of the problems with the current scale. We believe the term 'personal goals' in three (out of eight) items may be interpreted by respondents as only workrelated personal goals. Secondly, the omission of items relating to image violation in the non-work domain excludes the impact of non-work factors which, for some people, influence job turnover. This inference is supported by recent accounts that describe turnover as being inhibited by various sources of 'embeddedness' (Lee, Mitchell, Sablynski, Burton \& Holtom, 2004), in family and community contexts as well as work ones. It may however have been neglected in the constructs included in the unfolding model, even though research on the model has included questions about non-work matters. For example, although Donnelly and Quirin (2006) report that some women in their sample specified pregnancy or childbirth as a shock, they make little reference to other kinds of family pressures that typically fall to women - such as children entering secondary education, having to care for multiple children, and having to care for elderly relatives.

\section{Classification}

Although $23 \%$ of leavers were unclassifiable, the findings regarding classification are by no means all bad news for the unfolding model. Traditional accounts of turnover (e.g. Mobley, Griffeth, Hand \& Meglino, 1979), as well as the 
unfolding model, would struggle to describe many of the 81 unclassified cases. 27 leavers (in null pathways $1,4,8,9,11,12$ ) did not report job dissatisfaction. Over and above these, 7 (null pathways 5,7,14) did not search for alternatives. An additional 10 (null pathways 2,6,13) did not have a job offer on leaving. Failure to report job dissatisfaction is damaging to established accounts that show linkages between affect and thoughts of quitting, with job satisfaction as one of a series of stages in the decision to quit (see Maertz \& Campion, 1998). Failure to report search or offers is damaging to labor market accounts (Kirschenbaum \& Weisberg, 1994). In 11 of the remaining cases (null pathway 3), leavers reported shock, which traditional accounts of turnover do not incorporate.

Furthermore, a large proportion of respondents who were successfully classified by the unfolding model would pose problems to rival accounts. 117 classified leavers reported a shock. Over and above those, 13 left without a search, and an additional 15 left without evaluating alternatives. Thus, of the 271 classified leavers, 145 (54\%) would present problems for alternative accounts, because these generally do not incorporate the notion of shock, assuming instead that dissatisfaction develops gradually and that leaving follows job search and evaluation. So although many leavers were unclassified, there is evidence to support the underlying hypothesis of the unfolding model, namely that people quit in different ways. Indeed, even the presence of null pathways is evidence of heterogeneity in decision processes.

\section{Contextual Issues}

With respect to hypothesis 1a, the relationship between pathway and decision time could be influenced by the characteristics of the labor market in which this study was conducted. Nurses working in the NHS have a nationwide internal labor market, 
where, given current shortages, they are able to leave a specific Trust and find work quickly with another Trust (Morrell et al., 2004a). This sample also has significantly shorter tenure, about half that of the accountants in Lee et al. (1999). These factors may mean it is harder to discriminate between quits that are relatively deliberate, and quits where the decision is jolted by a shock. Both these kinds of quit decision, once made, can be implemented quickly. The implication for the unfolding model may be that it is not fine-grained enough to discriminate between the more impulsive, shock-triggered quits (path 3), vs. those that are more deliberate (path 4b) and already outlined in wellestablished accounts. In any case, Maertz and Campion (2004) suggest that shocks (either big or small) can prompt cognitions about quitting in any path, which would mean that paths 3 and $4 \mathrm{~b}$ could be combined. Furthermore, as Maertz and Campion point out, impulsive quits are usually made without having an alternative job offer. Yet in the context investigated here, alternative jobs are often easy to get, so quitting without an offer in hand is not necessarily impulsive.

Our test of Hypothesis 3a identified that job satisfaction was not significantly higher in path 3 than in path $4 \mathrm{~b}$. This is a significant challenge to the unfolding model because it muddies the distinction between shock-induced quits and those based on creeping dissatisfaction. In any case, there is not particularly compelling reason why an absence of shock should be associated with gradually increasing dissatisfaction (Maertz \& Campion, 2004). This may be a function of overall lower levels of satisfaction in our sample. In terms of other perceived work experiences, UK NHS nurses may typically experience more negative shocks than US accountants, because of institutional pressures, or resource constraints, as well as a range of other factors such as role 
conflict, shift work, low pay, feeling undervalued, lack of promotional opportunity, or perceived procedural injustice (Morrell et al., 2004a; Price \& Mueller, 1986).

\section{Limitations}

We acknowledge that, despite our measurement innovations, our study is subject to some of the same limitations as other work on the unfolding model. In order to ensure comparability with Lee et al. (1999), we did not overhaul the measures as much as we might otherwise have done. Our context, although different from Lee et al. (1999) and Donnelly and Quirin (2006), is still just one context, and cannot on its own demonstrate generalizability of the model. We are in good company in using retrospective reports as our data, and in some respects the unfolding model is designed to use such data. Nevertheless, there are problems with using retrospective self-reports, including retrospective rationalization, faulty attributions, oversimplification and memory lapses (Miller et al., 1997). Some of these limit any test of the model as currently formulated, given that it is retrospective. However, arguably retrospective reports have the advantage that a person can see the whole leaving process in a relatively holistic and measured way. Leaving a job tends to be a fairly salient and emotion-arousing event,

which enhances the ease with which it is remembered (Maertz \& Campion, 2004). Also, in this study, leavers were contacted at the latest 14 months after they had left, and in some cases they received a survey within two months of leaving. This represents an experimental improvement (see Table 2). Nonetheless, relying on retrospective selfreports is a limitation of this study. Future research could supplement leavers' responses with additional data, for example company records (Campion, 1991). They 
could track leavers at exit interview, and then reassess them later, to see if leavers' accounts were stable over time.

\section{Implications for research and practice}

Classification failures notwithstanding, the unfolding model captures a large percentage of decisions to leave and, we suggest, has higher ecological validity than extant models that do not incorporate the role of shock. Image violation plays a substantial part in most quits. Thus, leavers do indeed 'use different and distinct psychological processes when leaving' (Lee et al., 1996, p. 5). The current study also demonstrates the scope to link the unfolding model with well-established ideas regarding reasons (Campion, 1991) and avoidability (Abelson, 1987). All this suggests the model has 'practical adequacy' (Sayer, 1992), i.e. it warrants further development.

However, our data-based exploration suggested a systematic failure to classify some leavers. By showing that avoidability and the number of dependants were both significant predictors of classification status we demonstrate that there is systematic failure. In terms of the broader turnover literature, an implication of this study is that recent theoretical developments which give more weight to factors that go beyond the work setting (e.g. Lee et al., 2004, Maertz \& Griffeth, 2004), are very welcome.

We have concluded that the current image violation scale is unsatisfactory. Future tests should include items relating to personal goals in a separate section, or with items reworded to make it clear that respondents can consider life outside work. This would tap the influence of non-work domain variables (Cohen, 1999). Where there is a conflict between an otherwise satisfactory work life and a desire to pursue personal goals, valid responses will display a different (mixed) profile than in cases where there is congruence (and leavers are either generally dissatisfied, or generally satisfied). 
Current classification rules exclude leavers from paths 1, 2 and 4a where they believe getting another job is highly likely, because for classification purposes this is treated as the same as having an offer in hand. But this belief, and also the ease of getting a definite job offer, may be context-dependent, and a function of a tight labor market, rather than a true reflection of a type of decision. Where alternative opportunities are plentiful, leavers may report likely offers even if they quit in a scripted way. Future tests need to differentiate between background knowledge received through passive exposure to the job market (Kirschenbaum \& Weisberg, 1994), and that which influences the decision to quit. Therefore, we suggest that a key task in the future development and testing of the unfolding model is to distinguish between factors which do and do not play a role in leavers' decisions to leave. At present, the model is framed more in terms of factors being present vs. absent than in terms of playing a role in quitting vs. not playing a role.

There are at least three additional ways to incorporate labor market factors into the unfolding model. One is to examine how labor markets determine the decision frame for a quit - for example, in terms of perceived possible loss vs gain, and social norms around the wisdom or otherwise of quitting. Another is to refine the search construct to differentiate between active and passive modes of search. A third way is to incorporate scaled measures for evaluation and search that allow for sensitive assessment of deliberation. This could be used to determine cut-off points for division of leavers into different classes of deliberation (e.g. high, medium, low) that inform classification. This reflects that evaluation, assessment of likelihood and deliberation are not dichotomous states, but lie on continua. 
In some contexts, it may be difficult to intervene to prevent turnover. This is often for the same reasons that these decisions are difficult to model. Where alternative opportunities are plentiful it may only take a short time for employees to find other work. Managers may not have the authority or time to respond to the voicing of dissatisfaction, and by the time they have devised an intervention or recognized a problem, it may be too late (Maertz \& Campion, 2004). In any case, as our test demonstrates, many quits may be beyond the power of organizations to intervene. Nevertheless, some types of shock may be open to intervention (Morrell et al., 2004b). In this context, shocks frequently involved perceived injustices in the allocation of training opportunities and promotions. Awareness of the sources of shocks (as well as sources of creeping dissatisfaction) may help managers to intervene, preferably to stop shocks occurring in the first place. These interventions should take into account that in some contexts the factors pushing turnover may only need to be slight (given widespread low dissatisfaction), and the pull factors may be relatively strong (given labor market conditions). These are likely to have differential effects depending on the gender and typical non-work responsibilities of the employees. 


\section{References}

Abelson, M. A. (1987). Examination of avoidable and unavoidable turnover, Journal of Applied Psychology, 72, 382-386.

Allen, D. G., \& Griffeth, R. W. (2001). Test of a mediated performance - turnover relationship highlighting the moderating roles of visibility and reward contingency. Journal of Applied Psychology, 86, 1014-1021.

Amir, Y., \& Sharon, I. (1991). Replication research: A must for the scientific advancement of psychology. In Neuliep, J. (Ed.) Replication research in the social sciences (pp. 51-69). London: Sage..

Beach, L. R. (1990). Image theory. New York: Wiley.

Beach, L. R., \& Mitchell, T.R. (1998). The basics of image theory, in Beach L. R. (Ed.), Image theory: Theoretical and empirical foundations. Chichester: Wiley.

Bozeman, D. P., \& Perrewé, P. L. (2001). The effect of item content overlap on Organizational Commitment Questionnaire - turnover cognitions relationships. Journal of Applied Psychology, 86, 161-173.

Campion, M. A. (1991). Meaning and measurement in turnover. Journal of Applied Psychology, 76, 199-212.

Cohen, A. (1999). Turnover among professionals. Human Resource Management, 38, $61-75$.

Donnelly, D. P., \& Quirin, J. J. (2006). An extension of Lee and Mitchell's unfolding model of voluntary turnover. Journal of Organizational Behavior, 27, 59-77.

Eden, D. (2002). Replication, meta-analysis, scientific progress and $A M J$ 's publication policy. Academy of Management Journal, 45, 841-846. 
Edwards, J. R. (2002). The past, present and future of Organizational Behavior and Human Decision Processes. Organizational Behavior and Human Decision Processes, 87, 1-4.

Griffeth, R. W., Gaertner, S., \& Sager, J. K. (1999). Taxonomic model of withdrawal behaviors: the adaptive response model, Human Resource Management Review, 9 , $577-590$.

Hair, J. F., Anderson, R. E., Tatham, R. L., \& Black, W. C. (1998). Multivariate data analysis $\left(5^{\text {th }}\right.$ Edition). London: Prentice-Hall.

Hendrick, C. (1991). Replications, strict replications, and conceptual replications: are they important?. In J. Neuliep (Ed.). Replication research in the social sciences (pp. 41-49). London: Sage.

Hom, P. W., \& Kinicki, A. J. (2001). Toward a greater understanding of how dissatisfaction drives employee turnover, Academy of Management Journal, 44, 975-987.

Hosmer, D. W., \& Lemeshow, S. (1989). Applied logistic regression, London: Wiley.

Hubbard, R., Vetter D. E. \& Little, E. L. (1998). Replication in strategic management: scientific testing for validity, generalizability, and usefulness. Strategic Management Journal, 19, 243-254.

Johns, G. (2001). In praise of context. Journal of Organizational Behavior, 22, 31-42.

Kirschenbaum, A., \& Weisberg, J. (1994). Job search, intentions and turnover. Journal of Vocational Behavior, 44, 17-31.

Lee, T. W., \& Mitchell, T. R. (1994). An alternative approach: the unfolding model of voluntary employee turnover. Academy of Management Review, 19, 51-89. 
Lee, T. W., Mitchell, T. R., Holtom, B. C., McDaniel, L. S., \& Hill, J. W. (1999). The unfolding model of voluntary turnover: A replication and extension. Academy of Management Journal, 42, 450-462.

Lee, T.W., Mitchell, T.R., Sablynski, C.J, Burton, J.P., \& Holtom, B.C. (2004). The effects of job embeddedness on organizational citizenship, job performance, volitional absences and voluntary turnover. Academy of Management Journal, 47, 711-722.

Lee, T. W., Mitchell, T. R., Wise, L., \& Fireman, S. (1996). An unfolding model of voluntary employee turnover, Academy of Management Journal, 39, 5-36.

Loo, R. (2002). A caveat on using single-item versus multiple-item scales. Journal of Managerial Psychology, 17, 68-75.

Maertz, C. P., \& Campion, M. A. (1998). 25 years of voluntary turnover research: A review and critique. International Review of Industrial and Organizational Psychology, 13, 49-81.

Maertz, C. P., \& Campion, M. A. (2004). Profiles in quitting: integrating process and content turnover theory. Academy of Management Journal, 47, 566-582.

Maertz, C. P., \& Griffeth, R. W. (2004). Eight motivational forces and voluntary turnover: A theoretical synthesis with implications for research. Journal of Management, 30, 667-683.

Miller, C. C., Cardinal, L. B., \& Glick, W. H. (1997). Retrospective reports in organizational research. Academy of Management Journal, 40: 189-204. 
Mitchell, T.R., Holtom, B.C., Lee, T.W., Sablynski, C.J., \& Erez, M. (2001). Why people stay: Using job embeddedness to predict voluntary turnover. Academy of Management Journal, 44, 1102-1121.

Mobley, W.H., Griffeth, R.W., Hand, H.H., \& Meglino, B.M. (1979). Review and conceptual analysis of the employee turnover process. Psychological Bulletin, 86 , 493-522.

Morrell, K., Loan-Clarke, J., \& Wilkinson, A.J. (2004a). The role of shocks in employee turnover. British Journal of Management, 15, 335-349.

Morrell, K., Loan-Clarke, J., \& Wilkinson, A.J. (2004b). Organizational change and employee turnover. Personnel Review, 33, 161-173.

Nagy, M.S. (2002). Using a single-item approach to measure facet job satisfaction. Journal of Occupational \& Organizational Psychology, 75, 77-86.

Owen, F., \& Jones, R. (1994). Statistics, $\left(4^{\text {th }}\right.$ ed.), London: Pitman.

Peterson, M. F. (2001). International collaboration in organizational research. Journal of Organizational Behavior, 22, 59-81.

Price, J. L. (2000). Reflections on the determinants of voluntary turnover, International Journal of Manpower, 22, 600-624.

Price, J. L., \& Mueller, C. W. (1986). Absenteeism and turnover of hospital employees, Connecticut: JAI Press.

Rosenthal, R. (1991). Meta-analytic procedures for social research (Revised Ed.). Newbury Park California: Sage.

Sayer, A. (1992). Method in social science: a realist approach. London: Routledge.

Sheridan, J. E., \& Abelson, M. A. (1983). Cusp catastrophe model of employee turnover. Academy of Management Journal, 26, 418-436. 
Wanous, J. P., \& Reichers, A. E. (1996). Estimating the reliability of a single-item measure. Psychological Reports, 78, 631-634.

Wanous, J. P., Reichers, A. E., \& Hudy, M. J. (1997). Overall job satisfaction: How good are single-item measures? Journal of Applied Psychology, 82, 247-252. 
Table 1: Pathways in the Unfolding Model of Voluntary Turnover (Lee et al., 1999)

\begin{tabular}{|c|c|c|c|c|c|c|}
\hline Shock & Script & $\begin{array}{c}\text { Image } \\
\text { Violation }\end{array}$ & Satisfaction & $\begin{array}{c}\text { Search / Evaluate } \\
\text { Alternatives }\end{array}$ & $\begin{array}{c}\text { Likely } \\
\text { Offer }\end{array}$ & Path \\
Yes & Yes & N/A & N/A & No & No & 1 \\
\hline Yes & No & Yes & N/A & No & No & 2 \\
\hline Yes & No & Yes & No & Yes & Yes & 3 \\
\hline No & No & Yes & No & No & No & $4 \mathrm{a}$ \\
\hline No & No & Yes & No & Yes & Yes & $4 \mathrm{~b}$ \\
\hline
\end{tabular}

* In theory, no other routes are possible; any such null path would constitute theory falsification (Lee et al, 1999, p. 451). 
Table 2: Statistics Comparing Lee et al. (1999) with This Study

\begin{tabular}{|c|c|c|}
\hline & Lee et al. (1999) & This study \\
\hline Population & Accountants & Nurses \\
\hline Sample Size & 229 & 352 \\
\hline Response Rate & $20 \%$ & $31 \%$ \\
\hline $\begin{array}{l}\text { Time between leaving and } \\
\text { receiving survey }\end{array}$ & $30-60$ months & 2-14 Months \\
\hline Alpha: Image Violation & 0.82 & 0.89 \\
\hline Alpha: Job Satisfaction & 0.76 & 0.84 \\
\hline Mean Job Satisfaction & 3.39 & 2.84 \\
\hline S.D. Job Satisfaction & 0.51 & 0.7 \\
\hline $\begin{array}{rr}\text { DEMOGRAPHICS } & \text { Age } \\
& \text { Tenure } \\
\text { Sex }\end{array}$ & $\begin{array}{c}40 \\
8.1 \text { years } \\
69 \% \text { Male }\end{array}$ & $\begin{array}{c}35 \\
4.1 \text { years } \\
91 \% \text { Female }\end{array}$ \\
\hline $\begin{aligned} \text { CLASSIFICATION } & 1 \\
\text { PATH } & \end{aligned}$ & $6 \quad(2.6 \%)$ & $2 \quad(0.6 \%)$ \\
\hline 2 & $7 \quad(3.1 \%)$ & 0 \\
\hline 3 & $\begin{array}{ll}55 \quad(24 \%) \\
\end{array}$ & $115 \quad(32.7 \%)$ \\
\hline $4 \mathrm{~A}$ & $8 \quad(3.5 \%)$ & $\begin{array}{ll}1 & (0.3 \%)\end{array}$ \\
\hline $4 \mathrm{~B}$ & $\begin{array}{ll}136 & (59.4 \%)\end{array}$ & $153 \quad(43.5 \%)$ \\
\hline Unclassified & $17 \quad(7.4 \%)$ & $(23 \%)$ \\
\hline
\end{tabular}

